\title{
Epicardial fat thickness and carotid intima-media thickness in patients with type 2 diabetes mellitus
}

\author{
Pijush Kanti Mandal', Subhraprakash Pramanik², Koushik Mondal ${ }^{3}$, Shovan Kumar Das ${ }^{4}$, \\ Arpan Kumar Dey ${ }^{5}$, Samaresh Dutta ${ }^{6}$, Pranabesh Sarkar ${ }^{6}$, Amaresh Pramanik ${ }^{6}$ \\ ${ }^{1}$ Assistant Professor, Department of General Medicine, College of Medicine and Sagore Dutta Hospital, Kolkata, ${ }^{2} R M O$ \\ Cum Clinical Tutor, Department of General Medicine, Midnapore Medical College, Paschim Midnapore, ${ }^{3}$ RMO Cum \\ Clinical Tutor, Department of General Medicine, Burdwan Medical College, Burdwan, ${ }^{4}$ Physician (Specialist), Ghatal

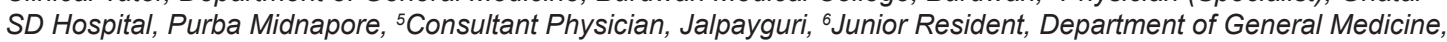 \\ College of Medicine and Sagore Dutta Hospital, Kolkata, India
}

Backgrounds: Epicardial adipose tissue thickness has been considered to be a possible cardiovascular risk indicator in recent reports. Aims and Objective: The aim of the study was to evaluate the relationship of echocardiographic epicardial fat thickness (EFT) with carotid intima-media thickness (CIMT), in patients with type 2 diabetes mellitus (T2DM). Materials and Methods: In this hospital based cross sectional observational study a total of 64 patients with T2DM (mean age $54.51 \pm 6.60$ years and $75.0 \%$ male) and 76 age and sex-matched non-diabetic control (mean age $54.97 \pm 6.11$ years and $71.1 \%$ male) were evaluated. Echocardiographic EFT and ultrasonographic CIMT were measured in all subjects. Results: Patients with T2DM had significantly increased EFT and CIMT than those of the nondiabetic controls $(6.15 \pm 0.99 \mathrm{~mm}$ versus $4.39 \pm 0.61 \mathrm{~mm}, \mathrm{P}<0.001$ and $0.77 \pm 0.09 \mathrm{~mm}$ versus $0.51 \pm 0.05 \mathrm{~mm}, \mathrm{P}<0.001$, respectively). EFT was correlated with CIMT $(r=0.724$, $P<0.001)$, duration of diabetes $(r=0.723, P<0.001)$ and fasting plasma glucose level $(r=0.542, P<0.001)$. Linear regression analysis showed that $\mathrm{CIMT}(\beta=0.358, \mathrm{t}=$ 3.658, $P<0.001)$ duration of diabetes $(\beta=0.324, t=3.268, P=0.001)$ and fasting plasma glucose level $(\beta=0.210, t=3.302, P=0.001)$ were found to be the independent predictors of EFT. Conclusion: The echocardiographic EFT was significantly higher in patients with T2DM; and it was well correlated with CIMT, duration of diabetes and fasting plasma glucose level as being the independent predictors of EFT.

Key words: Epicardial fat thickness (EFT), Carotid intima-media thickness (CIMT), Type 2 diabetes mellitus (T2DM)

\section{INTRODUCTION}

The incidence of type 2 diabetes mellitus tends to grow steadily worldwide and associated with higher risk of cardiovascular disease which is the leading cause of death now-a-days in diabetics. ${ }^{1}$ It has been already proved that the insulin resistance, obesity and diabetes mellitus are the proinflammatory states associated with increased adiposity. ${ }^{2}$ Epicardial adipose tissue is the visceral fat depot of the heart located on the surface of the ventricles and apex along the major coronary arteries ${ }^{3}$ and embryologically similar to the intra-abdominal visceral adipose tissue. ${ }^{4}$ The epicardial adipose tissue is not only an anatomic depot of fat but also serve as a local source of proinflammatory cytokines related to coronary artery disease. ${ }^{5}$ Therefore, EAT thickness has been considered to be a possible cardiovascular risk indicator. ${ }^{6,7}$ Transthoracic echocardiography (TTE), MRI and multislice CT scanning have been used as conventional methods for quantifying EAT. ${ }^{8}$ Assessment of EAT by TTE could be a simple and practical tool for cardiovascular 
risk stratification in clinical practice. ${ }^{3}$ Carotid intima-media thickness (CIMT) is a simple and inexpensive tool to assess the cumulative effect of atherosclerotic risk factors and is an independent predictor of future cardiovascular risk. ${ }^{9}$ The ultrasound-based measurement of CIMT has become a standard for assessing arteriosclerosis and is recommended by the American Heart Association for the non-invasive assessment of cardiovascular risk. ${ }^{10,11}$ Previous studies have reported that increased EAT is associated with CAD, metabolic syndrome (MetS) and obesity. ${ }^{12-16} \mathrm{In}$ the present study, we evaluated type 2 diabetic patients to investigate epicardial fat thickness by TTE and investigate its relationship with CIMT.

\section{MATERIALS AND METHODS}

In this hospital based cross sectional observational study a total of 64 patients with type 2 diabetes mellitus, having this diagnosis for at least 1 year, were consecutively included in the study and compared with 76 age and sex-matched non-diabetic control. T2DM was diagnosed according to the American Diabetes Association criteria. ${ }^{17}$ The study protocol was approved by our local ethics committee, and all patients gave their written informed consent to participate in the study. Exclusion criteria of the study were subjects with known ischemic heart disease, cerebrovascular disease, peripheral vascular disease, congestive heart failure, valvular heart disease, and chronic kidney disease. Medical history was obtained and physical examination was performed in all patients and controls. Blood samples for fasting blood glucose level were withdrawn by venepuncture following $12 \mathrm{~h}$ of fasting and were determined using standard laboratory methods.

Measurements of Epicardial Adipose Tissue Thickness: Each patient underwent a complete transthoracic echocardiographyusing the American Society of Echocardiography guidelines of measurement. ${ }^{18}$ Echocardiogram was performed using a Vivid 7 (General Electronic, Waukesha, Wisconsin, USA) with a 2.5-3.5 $\mathrm{MHz}$ transducer, placed on the III-IV left intercostal space along the parasternal line, with patients being supine in left lateral decubitus and the head of the bed kept at $30^{\circ}$. All examinations were performed by an experienced cardiologist, blind to the patient's clinical information. Epicardial fat was identified as the space or layer anterior to the right ventricle with decreased echo-reflectivity compared with themyocardiumand pericardium. Epicardial fat thickness (EFT) was measured in end diastole on the free wall of the right ventricle from the parasternal longand short-axis views, as previously described. ${ }^{19,20}$ The maximum values at any site were measured, and the average value was considered. Imaging constraints were used toensure that the epicardial fat thickness was not measuredobliquely. Parasternal long- and short-axis views allow the most accuratemeasurement of EAT on the right ventricle, with optimalcursor beam orientation in each view.

\section{Carotid Ultrasonography}

Carotid arterieswere evaluatedusing a Logiq 7 (General Electronic, Waukesha, Wisconsin, USA) with a 7.5 $\mathrm{MHz}$ transducer. All examinations were performed by an experienced radiologist, blind to thepatient's clinical information. Measurements involved a primarytransverse and longitudinal scanning of the commoncarotid artery, bifurcation, and internal carotid. The CIMT was measured on the far wall at $1 \mathrm{~cm}$ from bifurcation of thecommon carotid artery as the distance between the lumen intima interface and the media-adventitia interface. At leastthree measurements were performed on both sides, and theaverage measurement was taken as the CIMT. All measurements were made at a plaque-free site.

SPSS statistical software version 20 for Windows was usedfor all statistical analysis. Categorical variables were expressed as number and proportions, while continuous variables were expressed as mean and standard deviation. Chi-square $\left(\chi^{2}\right)$ test was used to compare groups regarding categorical variables. Continuous variables were comparedwith Student $t$-test while comparing parametric variablesbetween diabetic patients and controls. Correlation analysis was performed using Pearson or Spearman tests. Linear regression analysis was used to explore the independent determinants of EFT. Levels of statistical significance were set at a $P$ value $<0.05$.

\section{RESULT}

In this cross-sectional hospital based observational study we evaluated a total of 140 patients of whom 64 were diabetic and 76 were non-diabetic control.

The mean age and gender distribution in between diabetic patients and non-diabetic control had no significant difference ( $p$ value $>0.05$ ), i.e., the study groups were age and sex matched. In diabetic patients, the mean duration of diabetes was $7.23 \pm 1.61$ years. The numbers of smoker, hypertensive and dyslipidemic patient were more associated with diabetes compared to non-diabetic control. The family history of coronary artery disease was also higher in diabetics (Table 1).

The Epicardial fat thickness and Carotid intima-media thickness both were significantly higher in diabetic group of patients. The mean BMI and fasting blood glucose level were also high in diabetic patients compared to nondiabetic. 
Table 1: Baseline characteristics of the patients with diabetic and non-diabetic controls

\begin{tabular}{lccc}
\hline Parameters & DM & Control & Sig. \\
\hline Age (years) & $54.51 \pm 6.60$ & $54.97 \pm 6.11$ & 0.673 \\
Gender (male \%) & 75 & 71.1 & 0.601 \\
Duration of DM (years) & $7.23 \pm 1.61$ & - & - \\
Hypertensive (\%) & 56.2 & 34.2 & 0.009 \\
Smoker (\%) & 31.2 & 25 & 0.411 \\
Dyslipidemia (\%) & 64.1 & 40.8 & 0.006 \\
Family history of CAD (\%) & 28.1 & 14.5 & 0.047 \\
Epicardial fat & $6.15 \pm 0.99$ & $4.39 \pm 0.61$ & $<0.001$ \\
thickness (mm) & & & \\
Carotid intima-media & $0.77 \pm 0.09$ & $0.51 \pm 0.05$ & $<0.001$ \\
thickness $(\mathrm{mm})$ & & & \\
Body mass index $\left(\mathrm{kg} / \mathrm{m}^{2}\right)$ & $26.54 \pm 2.24$ & $25.66 \pm 2.30$ & 0.025 \\
Fasting glucose $(\mathrm{mg} / \mathrm{dl})$ & $141.85 \pm 22.99$ & $114.75 \pm 21.93$ & $<0.001$ \\
\hline
\end{tabular}

\begin{tabular}{lcc}
$\begin{array}{l}\text { Table 2: The bivariate correlations of the } \\
\text { epicardial fat thickness }\end{array}$ & \\
\hline Variable & $\mathbf{r}$ & P value \\
\hline Carotid artery intima-media thickness & 0.724 & $<0.001$ \\
Duration of DM (years) & 0.723 & $<0.001$ \\
Fasting glucose (mg/dL) & 0.542 & $<0.001$ \\
\hline
\end{tabular}

\begin{tabular}{|c|c|c|c|c|c|}
\hline \multirow{2}{*}{$\begin{array}{l}\text { Dependent } \\
\text { variable: } \\
\text { epicardial fat } \\
\text { thickness }\end{array}$} & \multirow{2}{*}{$\begin{array}{c}\begin{array}{c}\text { Standardized } \\
\text { coefficients }\end{array} \\
\text { Beta }\end{array}$} & \multirow[t]{2}{*}{$\mathbf{t}$} & \multirow[t]{2}{*}{ Sig. } & \multicolumn{2}{|c|}{$\begin{array}{c}95.0 \% \\
\text { Confidence } \\
\text { Interval for B }\end{array}$} \\
\hline & & & & $\begin{array}{l}\text { Lower } \\
\text { bound }\end{array}$ & $\begin{array}{l}\text { Upper } \\
\text { bound }\end{array}$ \\
\hline (Constant) & & 1.569 & 0.119 & -0.416 & 3.610 \\
\hline DM duration & 0.324 & 3.268 & 0.001 & 0.040 & 0.164 \\
\hline CIMT & 0.358 & 3.658 & 0.000 & 1.336 & 4.481 \\
\hline FBS & 0.210 & 3.302 & 0.001 & 0.004 & 0.015 \\
\hline
\end{tabular}

The epicardial fat thickness is significantly correlated with carotid artery intima-media thickness, duration of diabetes and fasting plasma glucose level (Table 2).

From simple linear regression analysis taking epicardial fat thickness as dependent variable, we found that the carotid artery intima-media thickness, duration of diabetes and fasting plasma glucose level as the independent predictor or risk factor of epicardial fat deposition (Table 3).

\section{DISCUSSION}

In this study, we observed that, (1) the patients with diabetes had increased epicardial fat and carotid intima media thickness compared to age and sex matched non-diabetic controls; (2) the epicardial fat thickness was correlated with CIMT, duration of diabetes and fasting plasma glucose level; and (3) the CIMT, duration of diabetes and fasting plasma glucose level were found to be the independent predictors of EFT.

Epicardial, mesenteric, and omental fats areoriginated from the same splanchno-pleuric mesoderm. ${ }^{4}$ The EAT produces inflammatory mediators such as interleukin (IL)-6, IL-1b, TNF alpha, and monocyte chemotactic protein (MCP-1) in patients with coronary artery disease $^{22}$ and expresses $m R N A s$ of adiponectin, resistin, leptin, IL-6, TNF-a, and CD-45. ${ }^{23}$ EAT play a role in thedevelopment and aggravation of CAD.,22-24 In addition, EFT has been shown to be related to MetS, abdominal visceral adiposity, subclinical atherosclerosis, non-alcoholic fatty liver disease, type $1 \mathrm{DM}$, impaired fasting glucose, andhypertension. ${ }^{19,20,25-29}$ There is very limited study investigating the relationship between T2DM and EFT. Recently, in a study performed by Kim et al., ${ }^{30}$ increased EAT thickness assessed by cardiovascular magnetic resonance (CMR) was an independent risk factor for significant coronary artery stenosis in asymptomatic type 2 diabetes. Mustafa Cetin et al., ${ }^{21}$ observed in their study that the echocardiographic EFT was significantly higher in patients with T2DM and also showed that EFT was strongly correlated with waist circumference and CIMT as being independent of sex. In another study reported by Wang et al., ${ }^{31}$ EAT volume assessed by cardiac multislice computed tomography was shown to be increased and was associated with unfavourable components of MetS and coronary atherosclerosis in type 2 diabetic patients.

In our study, we found that EFT and CIMT were increased in patients with T2DM compared to nondiabetic controls. It is also important that a positive linear and significant relationship between EFT with CIMT, duration of diabetes and fasting plasma glucose level were found in our study. CIMT is now increasingly used as a surrogate marker for atherosclerosis. According to these results, EFT may be used as amarker of subclinical atherosclerosis and disease progression in patients with T2DM. Further and large scale studies are required to support this hypothesis.

Although epicardial fat is readily visualized on high-speed CT and MRI, widespread use of these methods for its assessment is not practical. Echocardiographic EFT measurement in the current practice appears to be feasible, as well as reliable due to good reproducibility. ${ }^{19,20,32}$

\section{CONCLUSION}

In conclusion, we found that the echocardiographic EFT was significantly higher in patients with T2DM; and it 
was well correlated with CIMT, duration of diabetes and fasting plasma glucose level as being the independent predictors of EFT. From our study we may suggest that the echocardiographic assessment of EFT is a reliable marker of atherosclerosis and increased cardio-vascular risk in patients with T2DM. Further and large scale studies are needed to confirm these findings.

\section{REFERENCES}

1. Morrish NJ, Wang SL, Stevens LK and Keen H. Mortality and causes of death in the WHO multinational study of vascular disease in diabetes. Diabetologia 2001; 44(2):S14-S21.

2. Vela $D$, Buja LM, Madjid M, et al. The role of periadventitial fat in atherosclerosis. Archives of Pathology \& Laboratory Medicine 2007; 131:481-487.

3. lacobellis G, Corradi D and Sharma AM. Epicardial adipose tissue: anatomic, biomolecular and clinical relationships with the heart. Nature Clinical Practice Cardiovascular Medicine 2005; 2(10): 536-543.

4. Marchington JM, Mattacks CA and Pond CM. Adipose tissue in the mammalian heart and pericardium: structure, foetal development and biochemical properties. Comparative Biochemistry and Physiology 1989; 94(2): 225-232.

5. Sacks HS and Fain JN. Human epicardial adipose tissue: a review. American Heart Journal 2007; 153(6):907-917.

6. lacobellis $\mathrm{G}$ and Sharma AM. Epicardial adipose tissue as new cardio-metabolic risk marker and potential therapeutic target in the metabolic syndrome. Current Pharmaceutical Design 2007; 13(21): 2180-2184.

7. de Vos AM, Prokop M, Roos CJ, Meijs MFL, van der Schouw YT, Rutten A, et al. Peri-coronary epicardial adipose tissue is related to cardiovascular risk factorsand coronary artery calcification in post-menopausal women. European Heart Journal 2008; 29(6): 777-783.

8. Verhagen SN and Visseren FLJ. Perivascular adipose tissue as a cause of atherosclerosis. Atherosclerosis 2001; 214(1): 3-10.

9. O'Leary DH, Polak JF, Kronmal RA, Manolio TA, Burke GL and Wolfson SK. Carotid-artery intima and media thickness as a risk factor for myocardial infarction and stroke in older adults: cardiovascular health study collaborative research group. New England Journal of Medicine 1999; 340(1): 14-22.

10. Pignoli P, Tremoli $E$ and Poli A. Intimal plus medial thickness of the arterial wall: a direct measurement with ultrasound imaging. Circulation 1986; 74(6): 1399-1406.

11. Rajaram V, Pandhya S, Patel S, et al. Role of surrogate markers in assessing patients with diabetes mellitus and the metabolic syndrome and in evaluating lipid-lowering therapy. American Journal of Cardiology 2004; 93(11): 32C-48C.

12. Taguchi R, Takasu J, Itani $\mathrm{Y}$, Yamamoto R, Yokoyama K, Watanabe $\mathrm{S}$, et al. Pericardial fat accumulation in men as a risk factor for coronary artery disease. Atherosclerosis 2001; 157(1):203-209.

13. Gorter PM, van Lindert AS, de Vos AM, Meijs MF, van der Graaf Y, Doevendans PA, et al. Relation of epicardial and pericoronary fat to coronary atherosclerosis and coronary artery calcium in patients undergoing coronary angiography. American Journal of Cardiology 2008; 102(4): 380-385.

14. Rosito GA, Massaro JM, Hoffmann U, Ruberg FL, Mahabadi AA, Vasan RS, et al. Pericardial fat, visceral abdominal fat, cardiovascular disease risk factors, and vascular calcification in a community-based sample the
Framingham heart study. Circulation 2008; 117(5):605-613.

15. Okyay K, Balcioglu AS, Tavil Y, Tacoy G, Turkoglu $S$ and Abaci A. A relationship between echocardiographic subepicardialadipose tissue and metabolic syndrome. International Journal of Cardiovascular Imaging 2008; 24(6):577-583.

16. Gorter PM, van LindertAS, de Vos AM, Meijs MF, van der Graaf Y, Doevendans PA, et al. Quantification of epicardial and pericoronary fat using cardiac computed tomography; reproducibility and relation with obesity and metabolic syndrome in patients suspected of coronary artery disease. Atherosclerosis 2008; 197(2): 896-903.

17. Garber AJ, Moghissi ES, Buonocore D, Clark NG, Cobin RH, Eckel RH, et al. American College of Endocrinology and American Diabetes Association consensus statement on inpatient diabetes and glycemic control. Diabetes Care 2006;29:1955-1962.

18. Schiller NB, Shah PM, Crawford M, De Maria A, Devereux R, Feigenbaum $\mathrm{H}$, et al. Recommendations for quantitation of the left ventricle by two-dimensional echocardiography. American Society of Echocardiography Committee on Standards, Subcommittee on Quantitation of Two-Dimensional Echocardiograms. Journal of the American Society of Echocardiography 1989; 2(5): 358-367.

19. lacobellis G, Ribaudo MC, Assael F, Vecci E, Tiberti C, Zappaterreno A, et al. Echocardiographic epicardial adipose tissue is related to anthropometric and clinical parameters of metabolic syndrome: a new indicator of cardiovascular risk. The Journal of Clinical Endocrinology \&Metabolism 2003; 88(11): 5163-5168.

20. lacobellis G, Assael F, Ribaudo MC, Zappaterreno A, Alessi G, Di Mario U, et al. Epicardial fat from echocardiography: a new method for visceral adipose tissue prediction. Obesity Research 2003;11(2):304-310.

21. Cetin M, Cakici M, Polat M, Suner A, Zencir C and Ardic I. Relation of Epicardial Fat Thickness with Carotid Intima-Media Thickness in Patients with Type 2 Diabetes Mellitus. International Journal of Endocrinology 2013; Article ID 769175, 6 pages.

22. Mazurek T, Zhang L, Zalewski A, Mannion JD, Diehl JT, Arafat $\mathrm{H}$, et al. Human epicardial adipose tissue is a source of inflammatory mediators. Circulation 2003; 108(20):2460-2466.

23. Baker AR, Silva NF, Quinn DW, Harte AL, Pagano D, Bonser RS, et al. Human epicardial adipose tissue expresses a pathogenic profile of adipocytokines in patients with cardiovascular disease. Cardiovascular Diabetology 2006; 5:1-7.

24. de Feyter PJ. Epicardial adipose tissue: an emerging role for the development of coronary atherosclerosis. Clinical Cardiology 2011; 34:143-144.

25. lacobellis G, Pellicelli AM, Sharma AM, Grisorio B, Barbarini G and Barbaro $G$. Relation of subepicardial adipose tissue to carotid intima-media thickness in patients with human immunodeficiency virus. American Journal of Cardiology 2007; 99(10):1470-1472.

26. Yazıcı D, Ozben B, Yavuz D, Deneli O, Aydin H, Tarcin O, et al. Epicardial adipose tissue thickness in type 1 diabetic patients. Endocrine 2011; 40:250-255.

27. Colak Y, Karabay CY, Tuncer I, et al. Relation of epicardial adipose tissue and carotid intima-media thickness in patients with non alcoholic fatty liver disease. European Journal of Gastroenterology \& Hepatology 2012; 24(6):613-618.

28. lacobellis G, Barbaro $G$ and Gerstein HC. Relationship of epicardial fat thickness and fasting glucose. International Journal of Cardiology 2008; 128(3): 424-426.

29. Ero glu S, Sade L, Yıldırır A, Demir O and M"uderriso glu $H$. Association of epicardial adipose tissue thickness by echocardiographyand hypertension. Archives of the Turkish Society of Cardiology 2013; 41(2): 115-122. 
30. Kim HM, Kim KJ, Lee HJ, Hee TY, Yu HT, Moon JH, et al. Epicardial adipose tissue thickness is an indicator for coronary artery stenosis in asymptomatic type 2 diabetic patients: its assessment by cardiac magnetic resonance. Cardiovascular Diabetology 2012; 11:83.

31. Wang CP, Hsu HL, Hung WC, Yu TH, Chen YH, Chiu CA, et al. Increased epicardial adipose tissue (EAT) volume in type 2 diabetes mellitus and association with metabolic syndrome and severity of coronary atherosclerosis. Clinical Endocrinology 2009; 70(6): 876-882.

32. Chaowalit N, Somers VK, Pellikka PA, Rihal CS and LopezJimenez F. Subepicardial adipose tissue and the presenceand severity of coronary artery disease, Atherosclerosis 2006; 186(2): 354-359.

Authors Contribution:

PKM, SP, KM, SKD, AKD - Concept, Design, Manuscript writing, Review of Literature; SD,PS,AP- Data Collection, Literature Search, Review of Literature.

Source of Support: Nil. Conflict of Interest: None. 